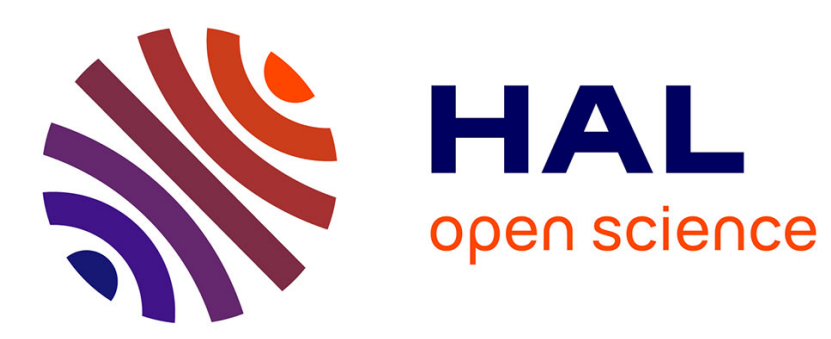

\title{
Improving Factory Resource and Energy Efficiency: The FREE Toolkit
}

\author{
Mélanie Despeisse, Steve Evans
}

\section{To cite this version:}

Mélanie Despeisse, Steve Evans. Improving Factory Resource and Energy Efficiency: The FREE Toolkit. IFIP International Conference on Advances in Production Management Systems (APMS), Sep 2015, Tokyo, Japan. pp.640-646, 10.1007/978-3-319-22756-6_78 . hal-01417629

\section{HAL Id: hal-01417629 \\ https://hal.science/hal-01417629}

Submitted on 15 Dec 2016

HAL is a multi-disciplinary open access archive for the deposit and dissemination of scientific research documents, whether they are published or not. The documents may come from teaching and research institutions in France or abroad, or from public or private research centers.
L'archive ouverte pluridisciplinaire HAL, est destinée au dépôt et à la diffusion de documents scientifiques de niveau recherche, publiés ou non, émanant des établissements d'enseignement et de recherche français ou étrangers, des laboratoires publics ou privés. 


\title{
Improving Factory Resource and Energy Efficiency: the FREE Toolkit
}

\author{
Mélanie Despeisse and Steve Evans \\ Institute for Manufacturing, University of Cambridge, United Kingdom \\ \{md621, se321\}@cam.ac.uk
}

\begin{abstract}
Eco-efficiency is defined as the concept of doing more with less; in other words, creating goods and services while preserving natural resources and reducing waste and pollution during manufacturing. This paper presents a toolkit for eco-efficiency at factory level: the Factory Resource and Energy Efficiency (FREE) toolkit. It contains five key elements; (1) see waste, (2) find solutions, (3) set targets, (4) assess yourself, and (5) create good habits. The FREE toolkit contains a range of games, tools and methods mapped against these five elements to integrate sustainability into factory activities. This paper presents the toolkit structure and an example of the journey for eco-efficiency.
\end{abstract}

Keywords: Eco-efficiency · Energy efficiency · Environmental performance · Resource efficiency $\cdot$ Sustainability $\cdot$ Sustainable manufacturing · Toolkit

\section{Introduction}

While factories are a source of economic and social value, they are also viewed as a cause of environmental problems. The emergence of concepts such as eco-efficiency, cleaner production, and industrial ecology $[1,2,3]$ challenges this negative view of manufacturing. These concepts promote a radical change in perception of the role of industry from causing environmental degradation to becoming a driver for sustainability. They bring together men, money, machines and materials into more efficient configurations to support the transformation of our society towards sustainability [4]. This paper focuses on eco-efficiency. It aims to reduce material and energy intensity, increase service intensity of goods and services, reduce dispersion of toxic materials, improve recyclability, use renewable resources, and extend product life [3].

Factories are a key determining factor of the efficiency with which resources are converted into products and services. However, environmental performance variation of up to $400 \%$ has been observed between factories producing similar products with similar technology [5]. This occurs at different levels, from variation across industry sectors to variation across the processes within a single factory (Fig. 1). 


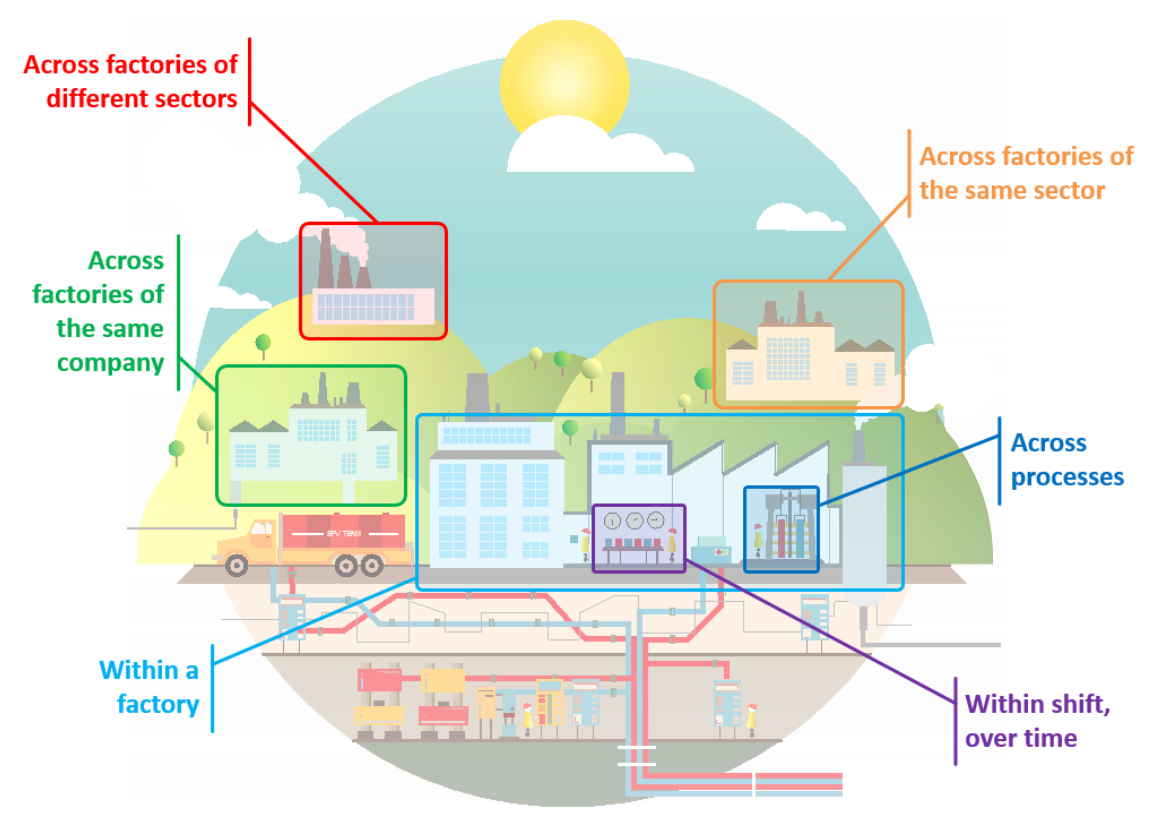

Fig. 1. Environmental performance variation at different levels (Illustration by Aanand Davé)

This research adopts a positive view of the role of industry in moving towards sustainability. The Factory Resource and Energy Efficiency (FREE) toolkit presented here seeks to promote eco-efficiency practices in factories. Eco-efficiency is defined as "doing more with less" as applied at factory level; in other words, creating goods and services while preserving natural resources and reducing waste and pollution during manufacturing. The following sections describe the toolkit structure and an example of its use with a generic sequence for getting started with eco-efficiency.

\section{The Toolkit Structure}

This paper presents the interim results of the Eco-Efficiency Grand Challenge - Environmental Performance Variation (EPV project) conducted by the EPSRC Centre for Innovative Manufacturing in Industrial Sustainability [6]. The EPV project aims to improve the overall sustainability of manufacturing by reducing environmental performance variation between factories and help elevate (future) factory sustainability performance. To address performance variation, a series of tools for factory eco-efficiency, ranging from games to advanced modelling techniques, were collected. This collection of tools forms the FREE toolkit presented in this paper. It aims to support the integration of eco-efficiency into daily activities. The toolkit is structured around five key elements. Each element is described below with a guiding question and associated activities for eco-efficiency. 
See waste. What is your waste worth?

In this first part of the toolkit, users learn to identify and value waste. This stage may seem trivial but companies often overlook their waste as they are part of "normal practice"; because the manufacturing operations are up and running, it is typically assumed that there is no need to improve the operations. However, proactive companies argue that there are always improvements to be made if we look for them, whichever level of performance you have. The more advanced the company is, the more challenging it becomes to see waste as the most obvious will be eliminated first. Once eco-efficiency activities are undertaken, waste which was previously ignored is made visible. After improvement, i.e. reduced or eliminated waste, the new state of operations becomes the new "normal practice", revealing previous practice to be "bad practice" as it was wasteful. Maintaining a good level of performance after improvement can be challenging; how to create good habits is addressed in the fifth element.

Find solutions. How can you remedy it?

The second element is concerned with reducing and eliminating the waste previously identified. This is done by providing users with concrete examples of eco-efficiency practices so that they may take action. The tools in this category include an improvement hierarchy with tactics for sustainable manufacturing and a library of good practices. Actions promoted by these tools can be quick wins to gain momentum, or more advanced solutions requiring data collection and analysis before improvements can be implemented. Quick wins are actions which can be readily taken and generate immediate savings, such as repairing leaks. More advanced approaches are likely to require more data for modelling and simulation.

Set targets. What's the size of the prize?

This element aims to encourage users to set ambitious targets by understanding the scale of the potential benefits. For instance, companies attempting to reduce their energy consumption typically start by proposing small targets of 5\%. However, improvements made by other companies show that savings of $20-80 \%$ are achievable [4]. It also shows that eco-efficiency activities are not about small, marginal improvements but can result in radical improvements if integrated into daily activities. Setting ambitious targets can encourage companies to view eco-efficiency as an approach for factory operations as opposed to an add-on on top of "normal practice".

Assess yourself. Where are you now?

The fourth element of the toolkit focuses on assessing current levels of performance through qualitative and quantitative methods. Quantitative assessment tools include key performance indicators (KPIs) and modelling tools. These quantitative methods provide a strong basis for target setting as suggested in the previous section. Assessment tools can also be qualitative and do not require any data collection. They can be used to aid understanding of eco-efficiency, identify strengths and weaknesses of the company in various dimensions of eco-efficiency, as well as identify areas with the best potential for improvements. 
Create good habits. Where to from here?

The final element of the toolkit aims to systematise eco-efficiency improvement activities. Tools in this section include training programmes, modelling tools and systematic use of indicators to track and further improve performance. Training is required to integrate eco-efficiency into daily activities and empower employees to seek and make resource efficiency improvements. By making eco-efficiency a work habit, it can be fully integrated into the factory operations on a daily basis and scale up the impact. Eco-efficiency cannot be considered as a one-time activity as it may result in only temporary improvement with the performance going back to pre-improvement levels as good practices are not maintained. This section of the toolkit is key to turning ecoefficiency good practices into standard practice.

\section{An Example of the Journey to Eco-Efficiency}

This section presents a collection of tools and a recommended sequence (Fig. 2) to get started with eco-efficiency. The journey and tools are mapped against the five elements of the FREE toolkit to provide structure and clarity. The tools presented here can help understanding, assessing and improving environmental performance with a step-wise approach. The sequence proposed is not necessarily the most appropriate for all companies but it is a generic one which will generate results. The FREE toolkit can also be used to develop a customised approach to eco-efficiency with more advanced tools.

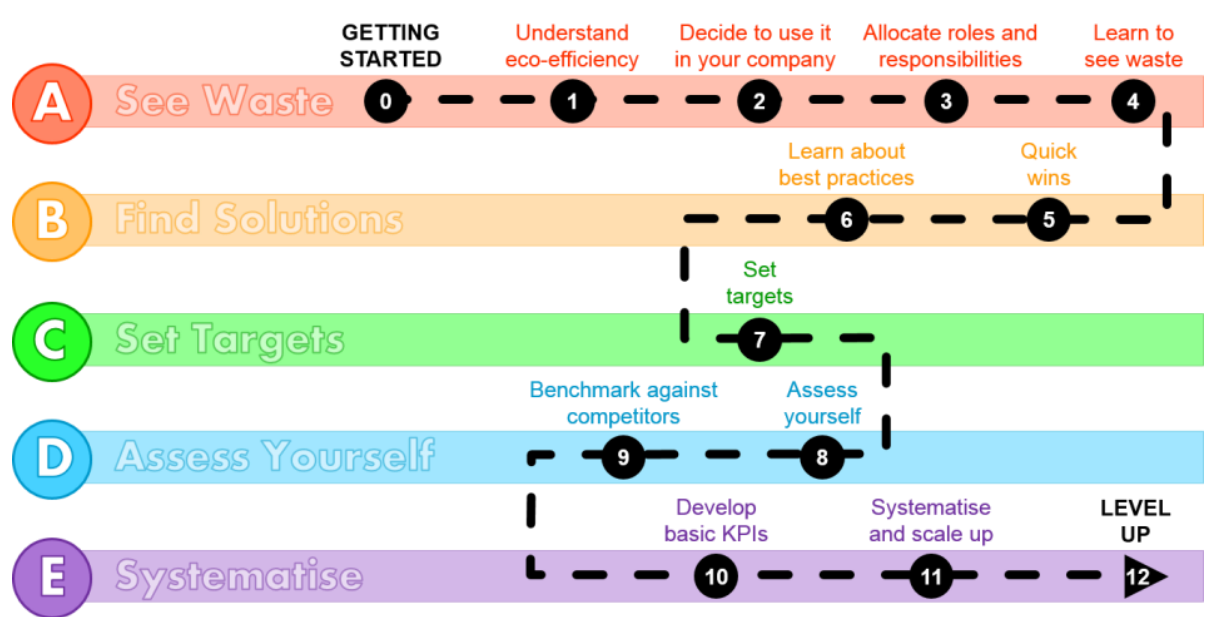

Fig. 2. Recommended sequence for getting started with eco-efficiency

Before implementing eco-efficiency, basic understanding of the concept and what it means in practice is required (step 1). This can be achieved with educational tools such as training and guide books $[3,7,8]$. These tools allow the company to see that becoming more eco-efficient is feasible and have significant benefits. This can lead to the company deciding to implement eco-efficiency in its operations (step 2). Responsibility 
then needs to be allocated so that designated people can lead the eco-efficiency activities (step 3).

Next, the company needs to learn to see waste (step 4) by looking at operations through a new lens to make waste visible. At this stage, low hanging-fruit and quick wins help gain momentum and engage more people in looking for improvements (step 5). One approach to identify immediate savings is to take a tour of the production facilities during non-operating hours and identify leaks or any equipment running which should be switched off. This exercise can be described as a "factory sensory experience" as it is guided by sound, smell, temperature, etc. The exercise can be enhanced through the use of technology (e.g. thermographic camera, electromagnetic and ultrasonic flow meter). Another exercise adopted by some companies is a collaborative treasure hunt. This exercise brings together experts from different factories to perform a walkthrough of the facilities and identify improvement opportunities [9]. Those experts may come from other companies and other industrial sectors. It allows knowledge and good practices to be transferred.

Further learning about good practices can be done through analysing documented cases [10] and databases [11] of best practices. Those information sources may be overwhelming as they contain a large number of examples and thus it is challenging to find specific, relevant information for a given company [12]. To simplify access to examples of sustainable manufacturing practices (step 6), a list of strategies and tactics [12] have been developed to support effective learning and ease access to specific solutions (Fig. $3)$.

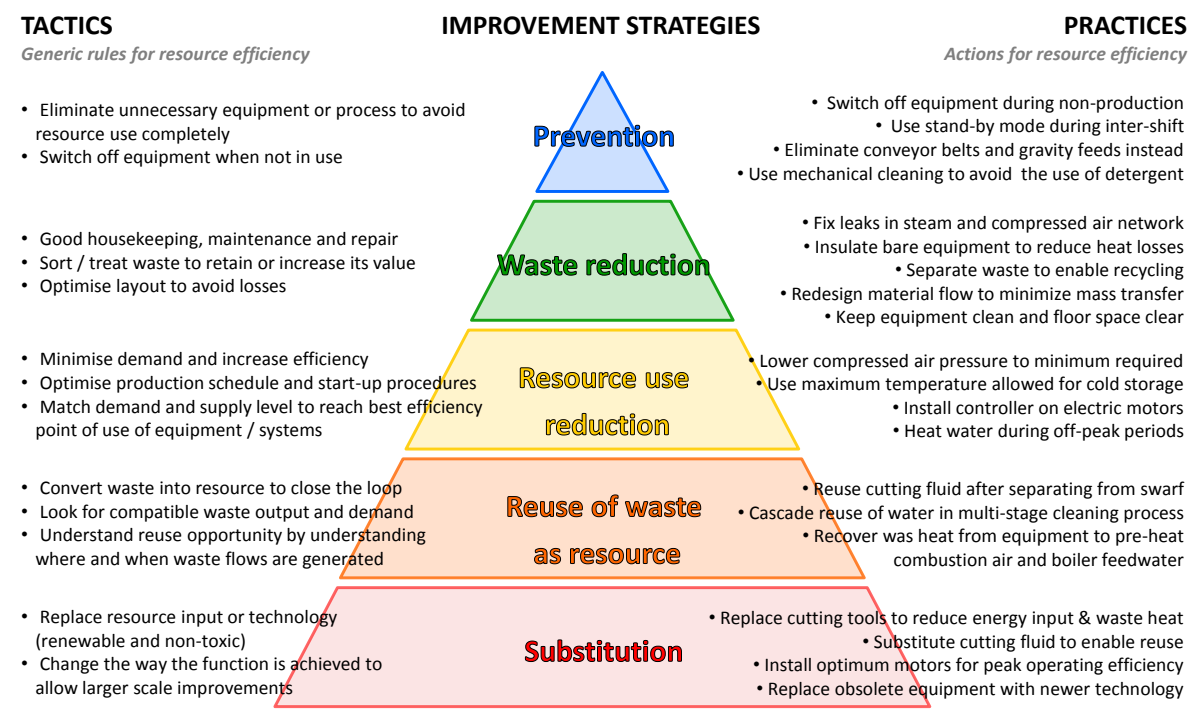

Fig. 3. Improvement strategies, tactics and examples of practices for sustainable manufacturing 
The next step proposed is to start using resource saving targets (step 7). By understanding the size of the prize, companies can set ambitious targets and make eco-efficiency a competitive activity in the company. Non-financial rewards and recognition have been identified as drivers for employee motivation, creativity and empowerment [13]. Understanding the size of the prize will help scale up the impact of eco-efficiency activities across the factory.

At this stage, qualitative assessment tools (step 8) can help identify areas of strength and weakness with no data collection required. Tools such as the Capability Assessment Grid for Eco-efficiency (CAGE) framework and the RAMP tool $[15,16]$ provide a basis for such qualitative assessment of companies' maturity in various dimensions of ecoefficiency. These assessments rely on the user's existing knowledge about the company in terms of resource management and environmental management system in place. In addition, these tools can be used for internal and external benchmarking (step 9). When used internally in a company, benchmarking enables intra- and inter-factory learning by transferring knowledge and practices from high to low performing areas.

While a qualitative assessment can help understand current level of maturity for ecoefficiency, a more quantitative assessment is needed to identify areas with the greatest opportunities for improvement, i.e. where most resources are being consumed and waste generated. A quantitative analysis can be supported by converting factory data into KPIs (step 10). Typical KPIs include energy, water, waste, and air emissions [4]. Factory modelling can help further the quantitative analysis and support the identification of improvements in a more systematic manner (step 11). Various modelling techniques can be used depending on the granularity of data available and the intended purpose of the factory model $[17,18]$. More advanced factory modelling techniques are particularly powerful to identify system-wide improvements $[17,19]$.

\section{Conclusions}

This paper introduced the FREE toolkit with examples of tools for eco-efficiency. The proposed journey to get started with eco-efficiency games and tools includes a selection of tools readily implementable. These tools are engaging, simple, and easy to use as they require little (if any) data. This helps overcome the first barriers to ecoefficiency (steps 1 to 3 in Fig. 2).

The examples provided are: collaborative treasure hunt and other factory games to identify areas of improvement, qualitative self-assessment tools to identify areas of strengths and weaknesses, good practices for sustainable manufacturing, and tools for making sense of factory data and developing performance indicators.

Most of the tools presented in this paper will play a role across multiple elements of the toolkit as they can address multiple aspects of eco-efficiency. For instance, a factory modelling tool can be used to quantify current performance as well as simulate the effect of scheduling or technological change on energy performance. Another example is using benchmarking tools to assess current performance and set targets. 
The five elements of the FREE toolkit can also provide a framework for companies to develop their own approach to eco-efficiency. As companies make progress and better understand how eco-efficiency fits into their activities, they can customise their journey using the five elements of the FREE toolkit to match their specific needs.

\section{Acknowledgements}

The author wishes to acknowledge the Engineering and Physical Sciences Research Council (EPSRC) for funding this project, the EPV team (Aannd Davé, Lampros Litos and Simon Roberts) for their participation and valuable inputs to the project, and the EPSRC Centre for Innovative Manufacturing in Industrial Sustainability and industrial partners for their support.

\section{References}

1. Ehrlich, P. R., Holdren, J. P., 1971. Impact of population growth. Science 171(3977), p. 1212-1217.

2. Schmidheiny, S., 1992. Changing course: A global business perspective on development and the environment. Cambridge, MA: MIT Press.

3. Lehni, M., Pepper, J., 2006. Eco-efficiency: Creating more value with less impact. World Business Council for Sustainable Development: North Yorkshire, UK. http://www.wbcsd.org/web/publications/eco_efficiency_creating_more_value.pdf [accessed 13/04/2015]

4. Evans, S., Bergendahl, M.N., Gregory, M., Ryan, C., 2009. Towards a Sustainable Industrial System, with Recommendations for Education, Research, Industry and Policy. University of Cambridge, Institute for Manufacturing, Cambridge.

5. Bocken, N., Morgan, D., Evans, S., 2013. Understanding environmental performance variation in manufacturing companies. Journal of Productivity and Performance Management 62(8), p. 856-870.

6. EPSRC Centre for Innovative Manufacturing in Industrial Sustainability. http://www.industrialsustainability.org/ [accessed 10/04/2015]

7. UNEP. Resource Efficient \& Cleaner Production (RECP) Programme. http://www.unep.org/resourceefficiency/Business/CleanerSaferProduction/ResourceEfficientCleanerProduction/tabid/102615/Default.aspx [accessed 10/04/2015]

8. Carbon Trust. Tools, guides \& reports. http://www.carbontrust.com/resources/guides

9. Next Manufacturing Revolution. New Resource Efficiency Tool: Collaborative Treasure Hunts. http://www.nextmanufacturingrevolution.org/new-resource-efficiency-tool-collaborative-treasure-hunts/

10. The Compressed Air Challenge. Library. https://www.compressedairchallenge.org/library/ [accessed 11/04/2015]

11. Industrial Assessment Centers Database. http://iac.rutgers.edu/database/ [accessed $11 / 04 / 2015]$

12. Roberts, S.J.F., Ball, P.D., 2014. Developing a Library of Sustainable Manufacturing Practices. Procedia CIRP Conference on Life Cycle Engineering 2014, p. 159-164.

13. Despeisse, M., Oates. M.R., Ball, P.D., 2013. Sustainable manufacturing tactics and crossfunctional factory modelling. Journal of Cleaner Production 42, p. 31-41. 
14. Amabile, T.M., 1998. How to kill creativity', Harvard Business Review 76(5), p. 76-87.

15. Litos, L., Evans, S., 2015. Maturity grid development for energy and resource efficiency management in factories and early findings from its application. Journal of Industrial and Production Engineering 32(1), p. 37-54.

16. Institute of Environmental Management \& Assessment (IEMA). Resource Action Maturity Planner (RAMP). https://www.iema.net/rmramp [accessed 10/04/2015]

17. Despeisse, M., Ball, P. D., Evans, S. and Levers, A., 2012. Industrial ecology at factory level - a prototype methodology. Proceedings of the Institution of Mechanical Engineers, Part B: Journal of Engineering Manufacture 226(10), p. 1648-1664.

18. Davé, A., Oates, M.R., Turner, C., and Ball P.D., 2015. Factory Modelling: The Impact of Data Granularity and Quality on Production and Building Architecture System Simulation Outputs.International Journal of Energy Sector Management, Emerald (accepted).

19. Davé, A, Ball, P.B., 2013. Factory Modelling: Data Guidance for Analysing Production, Utility and Building Architecture Systems. Proceedings of the 11th International Conference on Manufacturing Research 2013. 